\title{
Postoperative cardiac surgical care: an alternative approach
}

\author{
A Jindani, C Aps, E Neville, B Sonmez, K Tun, B T Williams
}

\begin{abstract}
Combined appropriate anaesthetic and surgical techniques have allowed increasing numbers of patients to be successfully managed in a general surgical recovery ward after cardiac surgery rather than in an intensive care unit. From 1983 to 1989 , 933 of 1542 patients undergoing open heart surgery were transferred to the general surgical recovery ward in the immediate postoperative period. Of these, $718(77 \%)$ had undergone coronary artery bypass grafts, sometimes combined with other procedures and 168 (18\%) had had cardiac valve replacements with or without other procedures. The remaining $47(5 \%)$ had had miscellaneous cardiac operations. Significant cardiac complications occurred in 29 (3\%) patients. The 24 hour chest radiograph was reported as abnormal (mainly atelectasis and effusion) in $63 \%$ of patients. Most resolved spontaneously or with physiotherapy. Twenty nine (3\%) patients were re-explored to achieve haemostasis. There were no deaths in the general surgical recovery ward. Thirty seven $(4 \%)$ patients had to be transferred to the intensive care unit for various reasons. The remaining 896 patients were transferred to the general ward after one night (871 patients) or two nights ( 25 patients) in the general surgical recovery ward. The average duration of stay in hospital for these patients was $\mathbf{9 \cdot 3}$ days. Because of the overall success of such management and the low rate of complications over $80 \%$ of patients are now managed in the general surgical recovery ward after open heart surgery. The resulting savings in capital expenditure of equipment, medical, nursing, and technical personnel are substantial, and there are major implications for the planning of new cardiothoracic units.
\end{abstract}

\section{(Br Heart J 1993;69:59-64)}

The increasing successful outcome after surgery, coronary artery bypass surgery in particular, has led to increasing referrals to cardiothoracic units. This constantly increasing demand has placed great strain on the facilities of such units and has resulted in long waiting lists in many centres.

These difficulties are further exacerbated by the limited number of beds available in intensive care units (ICU), as traditionally the postoperative management of patients undergoing open heart surgery is carried out in the ICU.

By the selection of suitable patients and an appropriate modification of the surgical and anaesthetic techniques it was thought possible that many of these patients could be successfully managed in a general surgical recovery ward. In 1983, in a pilot project, 103 carefully selected patients were managed in the surgical recovery ward in the immediate postoperative period before being returned to the general ward. After the successful outcome of that study $^{1}$ we now routinely use this method, which we report now.

\section{Patients and methods}

All patients undergoing uncomplicated open heart surgery were considered suitable for postoperative management in the general surgical recovery ward unless they had severe functional respiratory disorders, severe ventricular impairment requiring prolonged and substantial inotropic support, or intraaortic balloon counter pulsation. Also excluded were patients with significant renal or hepatic impairment, neurological disease, or malignant dysrhythmias. Diabetes was not a contraindication. Patients with a complicated perioperative course were sent directly to the ICU. Patients included in our management scheme were thus comparatively uncomplicated cases, the objective being that they should be in a haemodynamically stable condition, extubated, and therefore breathing spontaneously, and neurologically alert. Also they should have a normal core temperature $\left(37^{\circ} \mathrm{C}\right)$ and a minimal core to toe temperature gradient. Most patients needed no inotropic support and were prescribed fluid regimens requiring a minimum of nursing experience.

The surgical and anaesthetic techniques designed to achieve these objectives as well as the postoperative management of the patients have been described in detail, ${ }^{12}$ and are described briefly here.

SURGICAL TECHNIQUE

A standard technique is used throughout. For 
patients with coronary bypass grafting, a single right atrial cannula is used and cardiopulmonary bypass is achieved with moderate hypothermia to $32^{\circ} \mathrm{C}$. Wherever possible the left internal mammary artery is anastomosed to the left anterior descending vessel and reversed segments of the great saphenous vein from further bypass grafts. Distal coronary anastomoses are performed under intermittent ischaemic arrest and the proximal anastomoses constructed to the ascending aorta with the heart beating. For valvar replacements the patients are cooled to $28^{\circ} \mathrm{C}$ and crystalloid cardioplegia is used.

After completion of the final distal anastomosis or after completion of valve replacement, rewarming is started with the aim of returning the core temperature to $38^{\circ} \mathrm{C}$ before closure. During this period an active vasodilatation is produced pharmacologically by the anaesthetist, so that by closure the circulating blood volume is close to normal with minimal core to toe temperature gradient. These are the requirements for early extubation and further details are listed under the section on anaesthetic management.

During the period of rewarming and vasodilatation heparin is reversed with protamine, and decannulation proceeds. To be successful with this method it is vital to ensure optimal haemostasis before closure. Redivac drains $(6 \mathrm{~mm})$ are placed in the pericardium and mediastinum and the patient is transferred to the general surgical recovery ward.

\section{ANAESTHETIC MANAGEMENT}

A full description of the anaesthetic technique has been previously presented by Aps et al. ${ }^{2}$ For patients to be able to be extubated at the end of cardiopulmonary bypass, several criteria have to be met for which the anaesthetic technique has been designed. High dose opioid anaesthesia was thought to be inappropriate for immediate postoperative extubation. Similarly, the routine addition of an oral benzodiazepine to the papaveretum and hyoscine premedication was abandoned. Anaesthesia is induced with $100 \mu \mathrm{g}$ fentanyl and $10-15 \mathrm{mg}$ etomidate, together with $0.1 \mathrm{mg} / \mathrm{kg}$ pancuronium. Before cardiopulmonary bypass, maintenance of anaesthesia was with nitrous oxide in oxygen with either enflurane or halothane, according to the haemodynamic state.

Early in the series, sleep was maintained during bypass with small increments of fentanyl or etomidate, together with pancuronium for neuromuscular blockade. It soon became apparent that the pancuronium, used in doses sufficient to prevent diaphragmatic movement during hypercarbic conditions, presented difficulties with reversal at the end of the procedure. Atracurium was substituted and used during bypass in intermittent doses of 5-25 mg. Likewise, alfentanil in $1 \mathrm{mg}$ increments (to a total of $2-3 \mathrm{mg}$ ) is used instead of fentanyl at the start of and during bypass and rewarming. After extracorporeal circulation, anaesthesia is maintained with $66 \%$ nitrous oxide in oxygen, with further increments of fentanyl if required.
The total operative dose of fentanyl is limited to $250 \mu \mathrm{g}$. There have been no recorded cases of intraoperative awareness.

At the end of the operation, $2.5 \mathrm{mg}$ neostigmine and $0.6 \mathrm{mg}$ glycopyrronium are used to reverse neuromuscular blockade. The patient's trachea is extubated when the patient is awake and neurologically alert, able to maintain adequate ventilation while breathing spontaneously, have a stable circulation, and be warm, with a minimal core to peripheral temperature gradient. Restlessness or pain are adequately treated with intravenous morphine.

Before bypass, two units of the patients blood are removed so that after bypass, during the phase of vasodilatation, the intravascular volume and distribution are corrected by transfusion of the blood with the resulting core to toe temperature gradient returning to normal.

To optimise whole body heat exchange during rewarming, sodium nitroprusside or glyceryl trinitrate are infused at the maximum rate that still allows for an adequate arterial perfusion pressure. Temperature drop after rewarming is reduced by careful attention to patient insulation; a warming mattress and efficient lagged humidification system. Cardiopulmonary bypass is not discontinued until core (nasopharyngeal) temperature is $38^{\circ} \mathrm{C}$. Thus at the end of surgery the patient is alert, haemodynamically stable, self ventilating, and ready for transfer to the surgical recovery ward.

\section{POSTOPERATIVE MANAGEMENT}

The blood pressure, pulse, and electrocardiogram are directly measured and the central venous pressure is taken with a water manometer. Other measurements include central and peripheral temperature, urine output, and chest drainage.

Incremental doses of morphine or papaveretum produce analgesia and recently infusion pumps delivering 1 to $2 \mathrm{mg}$ of morphine have been introduced. Postoperative hypertension is controlled by $5-20 \mathrm{mg}$ of intravenous labetolol or $10-20 \mathrm{mg}$ of hydralazine. Fluid replacement is $60-90 \mathrm{ml}$ of crystalloid/hour, and colloid is given to replace losses and keep the central venous pressure around zero with reference to the sternal angle. Blood gas and potassium measurements are made regularly and supplements given as necessary. Chest radiographs are taken postoperatively and on the next morning. Routinely the chest drains are removed the next morning and the patients transferred back to the general ward.

\section{Results}

Between 1983 and 1989, 1542 patients underwent open heart surgery in one of the cardiac surgical services of the cardiothoracic unit at $\mathrm{St}$ Thomas' Hospital, London. Of these, 933 patients were transferred to the general surgical recovery ward immediately after the surgical procedure. Over the six years an increasing number of patients were managed in this way, whereas the number of patients sent to the intensive care unit in the immediate postoperative period fell (figure). 
Proportion of patients managed annually in the surgical recovery ward.

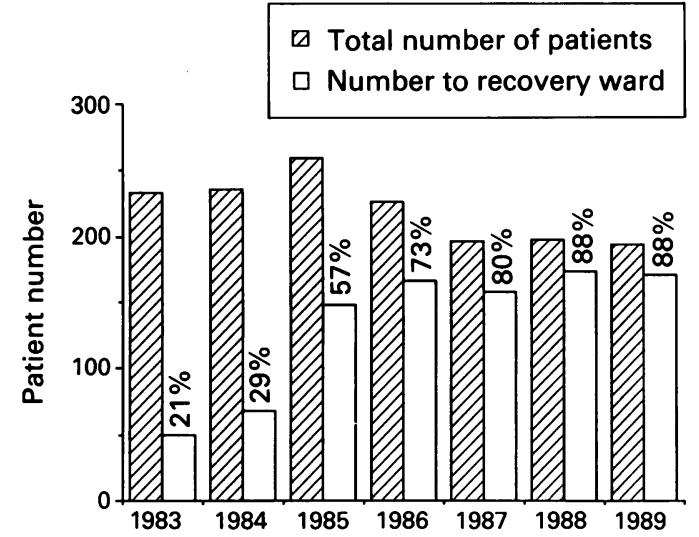

The age of the patients ranged from four to 80 (median 54.0 ) years. The number of patients with a history of myocardial infarction was: $0(50 \%), 1(34 \%), 2(12 \%), \geqslant 3(4 \%)$. Preoperative left ventricular ejection fraction ranged from $15 \%$ to $88 \%$ (mean $55 \%$ ) and the left ventricular end diastolic pressure ranged from -8 to 36 (mean 8 ) $\mathrm{mm} \mathrm{Hg}$.

The surgical procedures carried out were standard for a cardiothoracic surgical unit and included all types of open heart surgery with the exception of neonatal and paediatric cases. Table 1 shows the types of procedures carried out and the numbers of patients within each operative group. Cardiopulmonary bypass time ranged from 20 to 334 minutes (mean 81 minutes) and the aortic cross clamp times from 0 to 149 minutes (mean 40 minutes). Of the 933 patients, $894(96 \%)$ were extubated awake in the operating theatre before being transferred to the general surgical recovery ward. The rest were extubated in the general surgical recovery ward, usually for anaesthetic convenience.

All patients were rewarmed on bypass after completion of the last distal anastomosis, to a core temperature of $38^{\circ} \mathrm{C}$. The average postoperative core to toe temperature gradient was $5^{\circ} \mathrm{C}$ reducing to $2^{\circ} \mathrm{C}$ after two hours.

\section{BLOOD LOSS}

The postoperative blood loss from pericardial and mediastinal drains, in the first 18 hours was: $0-500 \mathrm{ml}$ in 422 patients $(45 \%), 500-1000 \mathrm{ml}$ in 389 patients $(42 \%), 1000 \mathrm{ml}+$ in 122 patients $(13 \%)$

Twenty nine patients were re-explored to achieve haemostasis and subsequently 28 of these were extubated at the end of the procedure.

Table 1 Patients within each operative group

\begin{tabular}{lc}
\hline Type of operation & Patients $(n)$ \\
\hline Single CABG & 47 \\
Double CABG & 156 \\
Triple CABG & 306 \\
Quadruple CABG & 163 \\
Five or more CABG & 29 \\
Single VR & 107 \\
Double VR & 22 \\
VR and CABG & 39 \\
CABG and LVA & 17 \\
Miscellaneous & 47 \\
Total & 933 \\
\hline CABG, coronary artery bypass graft; VR, valve replacement;
\end{tabular}

LVA, left ventricular ancurysmectomy.
Table 2 Important arrhythmias

\begin{tabular}{lc}
\hline Arrhythmia & No \\
\hline Atrial fibrillation & 10 \\
Ventricular tachycardia & 4 \\
Ventricular extrasystoles & 3 \\
Ventricular fibrillation & 2 \\
Bradycardia & 5 \\
Nodal rhythm & 3 \\
Complete heart block & 2 \\
Total of 933 patients & $29(3 \%)$ \\
\hline
\end{tabular}

Table 324 Hour chest radiograph

\begin{tabular}{lr}
\hline Appearance & No $(\%)$ \\
\hline Clear & $298(36)$ \\
Effusions & $197(24)$ \\
Atelectasis & $245(30)$ \\
Other & $83(10)$ \\
Total & $823(100)$ \\
\hline
\end{tabular}

\section{CARDIAC COMPLICATIONS}

Seven patients had a cardiac arrest. Of these, five were successfully resuscitated. In the remaining two patients the chest was opened in the general surgical recovery ward for internal cardiac massage. One patient had thrombosed vein grafts and was also haemorrhaging from the proximal anastomosis. After re-exploration in theatre the patient was transferred to the intensive care unit and died 24 hours later. The second patient died on the operating table while cardiopulmonary bypass was being reestablished. There were no further deaths in the patients managed in the general surgical recovery ward. Table 2 lists a further 29 cases of significant dysrhythmias.

\section{RESPIRATORY COMPLICATIONS}

Chest radiographs were analysed retrospectively by an independent radiologist. Radiographs taken on the first postoperative day were reviewed. Of the 933 cases, 823 had radiographs available for review. Of these 298 $(36 \%)$ had clear lung fields, $197(24 \%)$ had small or moderate pleural effusions and 245 $(30 \%)$ had varying degrees of atelectasis or collapse, mainly at the lung bases. In 46 cases there was radiological evidence of pulmonary oedema. Other abnormalities included significant mediastinal widening in three cases, small pneumothoraces in five, a haematoma in the lung apex in one case (probably related to central line insertion), and pericardial, mediastinal, or subphrenic air in 28 cases (table 3 ).

Table 4 Reasons for transfer of patients from surgical recovery ward to ICU

\begin{tabular}{lll}
\hline Reasons for transfer & No & Died in ICU \\
\hline Deteriorating arterial blood gases & 14 & 1 \\
$\begin{array}{l}\text { Cardiac arrest } \\
\text { Intra or perioperative myocardial } \\
\text { infarction }\end{array}$ & 7 & 1 \\
$\begin{array}{l}\text { Intra or perioperative cercbral } \\
\text { infarction }\end{array}$ & 7 & 4 \\
$\begin{array}{l}\text { Failed to breathe spontancously on } \\
\text { extubation }\end{array}$ & 2 & 0 \\
$\begin{array}{l}\text { Thrombosed vein grafts } \\
\text { Pyrexia and grand mal scizure in four } \\
\text { ycar old }\end{array}$ & 1 & 1 \\
Total of 933 patients & $37(4 \%)$ & 9 \\
\hline
\end{tabular}


Table 5 Comparison of intensive care unit with surgical recovery ward

\begin{tabular}{|c|c|c|}
\hline \multicolumn{2}{|c|}{ Intensive care unit } & \multirow{2}{*}{$\begin{array}{l}\text { General surgical recovery } \\
\text { ward }\end{array}$} \\
\hline 1 & $\begin{array}{l}\text { Capital equipment for } \\
\text { multiple pressure line } \\
\text { monitoring } x \text { ray film } \\
\text { screening facilities } \\
\text { haemodialysis capability }\end{array}$ & \\
\hline 2 & $\begin{array}{l}\text { Routine monitoring of } \\
\text { arterial LA-PA } \\
\text { pressures }\end{array}$ & $\begin{array}{l}\text { Simplified monitoring } \\
\text { through single arterial } \\
\text { pressure channel }\end{array}$ \\
\hline 3 & $\begin{array}{l}\text { Round the clock medical } \\
\text { presence }\end{array}$ & $\begin{array}{l}\text { Medical presence as } \\
\text { required }\end{array}$ \\
\hline 4 & $\begin{array}{l}\text { Intensive care trained } \\
\text { nurses }\end{array}$ & $\begin{array}{l}\text { Routine recovery ward } \\
\text { nurses }\end{array}$ \\
\hline 5 & $1: 1$ Nurse : patient ratio & $1: 3$ feasible \\
\hline 6 & $\begin{array}{l}\text { Technicians allocated to } \\
\text { service equipment }\end{array}$ & None \\
\hline 7 & $\begin{array}{l}\text { Substantial daily cost/ } \\
\text { patient }\end{array}$ & $\begin{array}{l}\text { Appreciably lower cost/ } \\
\text { patient }\end{array}$ \\
\hline
\end{tabular}

PATIENTS TRANSFERRED TO INTENSIVE CARE UNIT FROM GENERAL SURGICAL RECOVERY WARD Of the 933 patients initially managed in the general surgical recovery ward 37 (4\%) required subsequent transfer to the intensive care unit. Table 4 lists the reasons for transfer. Of these, nine patients died in the intensive care unit and the remaining 28 were eventually returned to the general ward.

Of the remaining 896 patients, $871(97 \%)$ were returned to the general ward after one night and $25(3 \%)$ after two nights in the general surgical recovery ward. Four further patients died before discharge from hospital. The perioperative mortality for the group was $1 \cdot 5 \%$. The median hospital stay for the surviving 919 patients was $9 \cdot 3$ (range 6-44) days.

\section{COST COMPARISONS}

An independent costing of cases was made by the accounts department at St Thomas' Hospital, comparing the cost of treating a patient in the general surgical recovery ward with that of treating a similar patient in the hospital intensive care unit. Tables 5 and 6 show the results. There is a rough saving of $£ 750$ for each case at St Thomas' Hospital.

\section{Discussion}

With the success of modern cardiac surgery, increasing referrals are made to hospital cardiothoracic services. Previously one of the main limiting factors to patient throughput in cardiac surgical units was the availability of intensive care unit beds, which resulted in increasing length of waiting lists and inefficient use of surgical resources.

A method of patient management was therefore devised, as described in this paper, for suitable cardiac cases to be managed post-

Table 6 True cost of cardiac operations at St Thomas's Hospital

\begin{tabular}{llll}
\hline & \multicolumn{3}{c}{ Cost in pounds sterling } \\
\cline { 2 - 4 } Operation & $I C U$ & SRW & Saving \\
\hline CABG & $3383 \cdot 09$ & $2642 \cdot 92$ & $740 \cdot 17$ \\
Single valve replacement & $5232 \cdot 41$ & $4474 \cdot 24$ & $758 \cdot 17$ \\
Double valve replacement & $7032 \cdot 41$ & $6274 \cdot 24$ & $758 \cdot 17$ \\
Average & & & $752 \cdot 17$ \\
\hline ICU, intensive care unit; SRW, surgical & recovery ward; & s. \\
CABG, coronary artery bypass graft.
\end{tabular}

operatively without intensive care unit trained personnel in the environment of the general surgical recovery ward. We previously published the results of a pilot study of 103 cases so managed, ${ }^{1}$ and encouraged by the results, now routinely adopt this technique for patients who we do not consider as high risk by virtue of severe cardiac, respiratory, or other major subsystem disease. With the scrupulous attention paid to the surgical and anaesthetic techniques outlined, most of our open heart surgery patients are able to be managed in a general surgical recovery ward and only a small proportion are managed in the intensive care unit (figure). As this is dependent on the patient being alert and self ventilating it is noteworthy that $96 \%$ of the patients transferred to the general surgical recovery ward were self ventilating and the rest were extubated within a few hours.

The subsequent fate of the 933 patients is important as a significant morbidity and mor- 8 tality would be a deterrent to the management of the patients in this way. The advantages of 0 early extubation have been pointed out, ${ }^{1}$ but ㅇ these should be weighed against the morbidity and mortality that results from such management.

Cardiac complications are potentially lethal unless rapidly corrected. Of the seven patients who suffered cardiac arrest, five were successfully resuscitated either by appropriate pharmacological intervention or DC shock and although they were transferred to the intensive care unit their subsequent progress was uneventful. Another 29 patients suffered dysrhythmias that required appropriate pharmacological intervention. All were later discharged from hospital (table 2).

In a comprehensive review of extracardiac complications of cardiac surgery the authors have listed 10 separate cardiac and pulmonary complications found in the period immediately after cardiac surgery. ${ }^{3}$ Most of the pulmonary complications they describe were found in our patients. In most they resolved either spontaneously or with physiotherapy. The reported rate of atelectasis was only $30 \%$ among the $88 \%$ of $x$ ray films that were available of assessment. This is much lower than the rates of $60 \%-88 \%$ reported in other studies. ${ }^{45}$

The rate of pleural effusions reported in this study $(24 \%)$ is slightly higher than that of $16 \%$ found in the pilot study ${ }^{1}$ but this may be due to the increased number of internal mammary artery grafts now used in coronary artery bypass procedures.

Of particular interest are the 37 patients who had to be transferred to the intensive care unit from the general surgical recovery ward for various reasons (table 4). In any group of patients undergoing major cardiac surgery the potential for the development of serious complications exists. In $4 \%$ of our patients these complications were judged to be serious enough to transfer the patient to the intensive care unit. A quarter of these patients ( $1 \%$ of the total group) died in the intensive care unit. Our experience suggests that those patients who had an intra or perioperative cerebral infarction 
should be transferred straight to the intensive care unit rather than the general surgical recovery ward.

The blood loss was greater than $1000 \mathrm{ml}$ in only $13 \%$ of the patients. Of the 29 patients who were re-explored for excessive bleeding not all had bled a large volume. A proportion of these patients were re-explored because of the sudden increase in tube drainage that had previously been minimal. Their subsequent recovery was uneventful.

The advantages of early extubation by the immediate restoration of spontaneous ventilation and avoidance of extra sedation have already been pointed out. ${ }^{1}$ Other systems may benefit as well. Renal dysfunction after open heart surgery is a well recognised complication with a significant rate of mortality. ${ }^{6}$ Alterations in intrarenal blood flow, decrease in total renal blood flow, glomerular filtration rate, and urinary flow by continuous positive pressure ventilation are well documented phenomena. Koning et al have shown a clear relation between the development of acute renal failure and the duration of positive pressure ventilation after open heart surgery. ${ }^{7}$ In the present study only two patients developed acute renal failure. One patient developed acute toxic epidermal necrolysis due to a staphylococcal infection on the 10th postoperative day. He subsequently developed acute renal failure and died 10 days later. The second patient developed a sternal wound infection, septicaemia, and renal failure, and died four weeks after the operation. As both developed renal failure several days after the operation their management in the general surgical recovery ward can not be implicated in the development of this complication.

In the earlier study the patients were carefully selected. None had had more than two myocardial infarctions and the ejection fraction was above $45 \%$. $^{1}$ Further, the operative procedures were mostly coronary artery bypass grafts with limited cardiopulmonary bypass and aortic cross clamp times. In our present study none of these criteria were applied as a means of selecting patients for management in the general surgical recovery ward. Moreover, the contention that cooling below $32^{\circ} \mathrm{C}$ would present difficulties with full rewarming ${ }^{1}$ did not hold as the patients undergoing single valve replacement were cooled to $28^{\circ} \mathrm{C}$ and those undergoing double valve replacement to $25^{\circ} \mathrm{C}$.

The overall hospital mortality for this group of patients was $1.5 \%$. This compares favourably with the reported rate of $2.37 \%$ in a nonrandomised surgical cohort undergoing artery bypass graft. ${ }^{8}$ The average duration of stay in hospital was 9.3 days, this too was lower than that reported of $12 \cdot 8$ days. $^{6}$

It could be argued that the management of these patients in the general surgical recovery ward is exactly the same as that in the intensive care unit. It is our contention, however, that significant differences exist in both capital expenditure and manpower needs between the general surgical recovery ward and intensive care unit (table 5). Table 6 shows the resulting decrease in costs. The resulting decrease in the number of days spent in hospital after operation are also evident and constitute a further area of financial savings. There are also significant planning implications in this work for new cardiothoracic units. It will not be necessary to provide such large intensive care units; most patients may be treated in a simple recovery area, with a small intensive care unit for patients experiencing complications.

We conclude that most patients undergoing open heart surgery may be safely managed in a general surgical recovery ward after operation with many advantages to both the patient and the economics of the exercise.

We thank Sundhiya Mandalia of the Department of Community Health, St Thomas' Hospital for her invaluable help in the analysis of the data.

1 Hutter JA, Aps C, Hemsi D, Williams BT. The managemen of cardiac surgical patients in a general surgical recovery ward. J Cardiovasc Surg 1989;30:273-6.

2 Aps C, Hutter JA, Williams BT. Anaesthetic managemen and post-operative care of cardiac surgical patients in a general recovery ward. Anaesthesia 1986;41:533-7.

3 Thorsen MK, Goodman LR. Extracardiac complications of cardiac surgery. Seminars in Roentgenology 1988;23:32-48.

4 Gale GD, Teasdale SJ, Sanders DE. Pulmonary atelectasis and other respiratory complications after cardiopulmonary bypass and investigation of aetiol cardiopulCanadian Anaesthetists Society Journal 1979;26:15.

5 Carter AR, Sostman HD, Curtis AM. Thoracic alterations after cardiac surgery. American Journal of Roentgenology 1983;140:475-81.

6 Alfieri A, Kotter MN. Non-cardiac complications of open heart surgery. Am Heart J 1990;119:149-58.

7 Koning HM, Koning AJ, Leusink JA. Serious acute renal failure following open heart surgery. Thorac Cardiovasc Surg 1985;33:283-7.

8 Kennedy JW, Kaiser GC, Fisher LD. Clinical and angiographic predictors of operative mortality from the collaborative study in coronary artery surgery (CASS) Circulation 1981;63:793-802.

\section{Comment}

The need for access to an intensive care unit is perceived to add expense and create a bottleneck to the provision of cardiac surgery. The "alternative approach" to postoperative cardiac surgical care described by Jindani and colleagues addresses an important issue but the paper met a mixed response from our advisors. The editors thought that the approach was of sufficient importance to be seen by the readers of the British Heart Journal who could form their own opinions as to whether the authors had made their case, but the editors also decided to publish the paper with an editorial comment that includes the salient points raised by the advisors.

To put the report in context it is important to remember that the facilities and staff used to treat patients after cardiac surgery differ considerably. At one end of the spectrum some hospitals nurse cardiac surgical patients in the general intensive care unit of the hospital under the supervision of a hierarchical team of specialist intensive care physicians. At the other extreme are specialist cardiac intensive 